\title{
SABERES, LUGARES E ARTÍFICES: HORIZONTES HISTÓRICOS, TEÓRICOS E METODOLÓGICOS DA BIBLIOGRAFIA
}

O Fórum Internacional A ARTE DA BIBLIOGRAFIA, concebido em 2014, por Andre Vieira de Freitas Araujo, Giulia Crippa e Gustavo Saldanha, resulta do desejo e da força originados e empregados em um programa de estudos cujo foco está no reconhecimento e atravessamento dos pântanos bibliográficos.

O "IV Seminário Internacional A Arte da Bibliografia: relações históricoepistemológicas entre Bibliografia e Biblioteconomia", realizado pelo Departamento de Biblioteconomia da Universidade Federal do Espírito Santo $(\text { UFES })^{1}$, na cidade de Vitória, em dezembro de $2017^{2}$, sob a coordenação geral de Andre Vieira de Freiras Araujo (UFRJ), representou um momento de consolidação no percurso realizado nas edições anteriores, respectivamente no Rio de Janeiro (UFRJ, 2014), em São Paulo (USP, 2015) e em Belo Horizonte (UFMG, 2016).

O evento (Fig. 1), cuja realização envolveu também a direção de pósgraduação da UFES e a direção do Centro de Ciências Jurídicas e Econômicas da UFES, apresentou claramente seu papel de destaque na internacionalização da pesquisa, bem como sua interinstitucionalidade aberta, contando com as contribuições de três grandes referências estrangeiras no campo dos estudos bibliográficos e no desenvolvimento das pesquisas nacionais.

\footnotetext{
1 Um agradecimento especial a todos os colegas do Departamento de Biblioteconomia da UFES, em especial à Profa. Dra. Neusa Balbino, cuja interlocução e dedicação foram fundamentais para consolidação do evento.

2 De característica itinerante, o Seminário Internacional A Arte da Bibliografia ocorrerá em 06 e 07 de dezembro de 2018, em Recife. Esta edição está sendo organizada e realizada pelo Fórum Internacional A Arte da Bibliografia e pelo Programa de Pós-Graduação em Ciência da Informação da Universidade Federal de Pernambuco (PPGCI UFPE). A V edição, que conta com a participação de convidados franceses e portugueses, tem como novidade a abertura para submissão de trabalhos, o que ampliará o número de pesquisadores sobre Bibliografia em todas as declinações possíveis. Sobre o evento, ver: https://www.ecceliber.org/a-arte-dabibliografia
} 
Figura 1 - IV Seminário Internacional "A Arte da Bibliografia: relações históricoepistemológicas entre Bibliografia e Biblioteconomia” (UFES, 2017) ${ }^{3}$

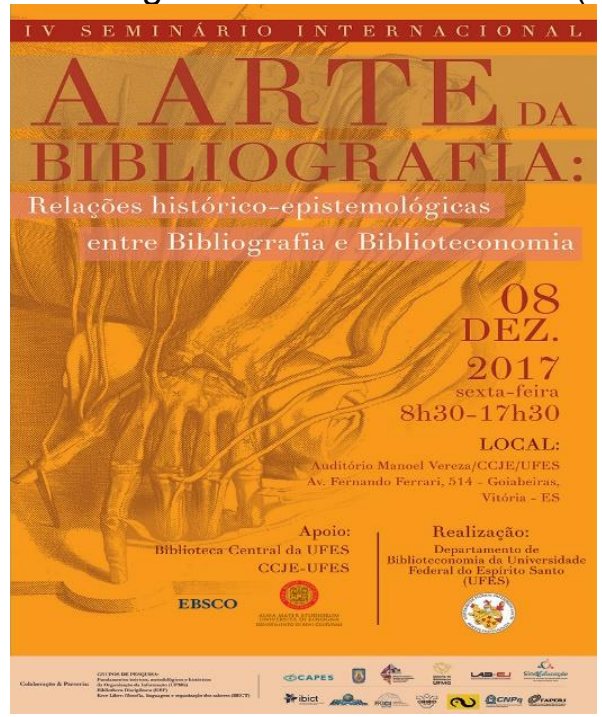

Fonte: Os Autores.

Ao lado dessas contribuições, os pesquisadores brasileiros participantes mostraram a centralidade das pesquisas bibliográficas em termos de vanguarda de autores, fontes e abordagens para a Ciência da Informação, que ofereceram o lastro para uma revisão aprofundada do foco das reflexões. Destaca-se, por exemplo, a contribuição de Fiammetta Sabba, da Universidade de Bolonha, cuja discussão histórica e epistemológica através de um cotejamento crítico e de uma aprofundada análise de dois autores como Ebert e Schrettinger revela a Bibliografia como "lugar" de disputas abertas e de caminhos variados, bem distante de ser um território de consensos.

Junto à paisagem rica da História da Bibliografia, as proposições de Attilio Mauro Caproni, Professor Titular de Bibliografia nas Universidades de Udine e Florença, um dos maiores nomes da Bibliografia italiana do século XX, em conferência gravada intitulada "Sapere aude (dizia Kant): a Bibliografia, uma ordem do discurso no Século XXI?", coloca em discussão as certezas lineares de certa visão positiva e tecnológica do nosso tempo.

Andrea Capaccioni, docente da Universidade de Perugia, contribuiu ${ }^{4}$ em moldar uma "espessura" maior ao tecido bibliográfico, multiplicando as abordagens epistemológicas acerca das funções e dos escopos possíveis da Bibliografia, a partir da discussão acerca do "sentido amplo" e "sentido estrito" da disciplina.

\footnotetext{
${ }^{3}$ Arte: Rodrigo de Araujo.

${ }^{4} \mathrm{O}$ artigo de Capaccioni não compõe o presente dossiê
}

Inf. Inf. Londrina, v. 23, n. 2, p. 01 - 03, maio/ago. 2018.

http://www.uel.br/revistas/informacao/ 
Marilda Lara (USP), responsável pela conferência de abertura do evento, discutiu o conceito de bibliografia examinando as origens do trabalho bibliográfico, as relações entre o termo, o conceito e suas definições ao longo do tempo, sua tipologia e função de mediação.

Os leitores poderão apreciar os aprofundamentos históricos de Andre Vieira de Freitas Araujo (UFRJ) sobre a arte de indicialização em Conrad Gesner (a partir da apresentação e tradução pioneira, no contexto iberoamericano, do texto latino gesneriano), bem como de Marcelo Nair dos Santos (UFES), que oferece ao leitor um panorama sobre as contribuições de Maunsell à catalogação. Ainda de uma perspectiva histórica, oferecemos uma contribuição sobre as práticas bibliográficas na Arte a partir de Giulia Crippa (USP).

De um ponto de vista epistemológico, o leitor poderá conhecer as contribuições à Bibliografia dos franceses Robert Estivals e Jean Meyriat, em artigo de autoria de Gustavo Saldanha (IBICT-UNIRIO) e de Viviane Couzinet (Université Paul Sabatier - Toulouse - França).

Na perspectiva epistemológica, Maira Cristina Grigoleto (UFES) contribui com suas reflexões de matriz foucaultiana sobre episteme e mediações, nas intersecções da Bibliografia e do documento.

Não está ausente a contribuição relacionada à vertente tecnológica do universo bibliográfico, frente discutida ${ }^{5}$ por Daniela Lucas da Silva Lemos (UFES) e Renato Souza Rocha (Fundação Getúlio Vargas) que abordam a representação bibliográfica pelo viés das ontologias.

Considerando que a Bibliografia é, sobretudo, a organização do saber, isto é, representação do método no qual entra em jogo o andamento de cada exame do intelecto (CAPRONI, 20076), esperamos que a proposta desse dossiê amplie cada vez mais o interesse para os temas bibliográficos, envolvendo crescentemente mais pesquisadores na rede e no Fórum Internacional A ARTE DA BIBLIOGRAFIA!

\section{Giulia Crippa \\ Gustavo Saldanha André Vieira de Freitas Araujo}

\footnotetext{
${ }^{5}$ A comunicação oral contou com participação de Rachel Cristina Mello Guimarães (UFES).

${ }^{6}$ CAPRONI, Attilio Mauro. L'inquietudine del sapere: scritti di teoria della Bibliografia. Milano: Sylvestre Bonnard, 2007.
} 